\title{
Coronavirus disease 2019 in neonates
}

\author{
Jade Irene Linardi* \\ Faculty of Medicine, Atma Jaya Catholic University, Jakarta, Indonesia \\ Received: 01 March 2021 \\ Accepted: 19 March 2021

\section{*Correspondence:} \\ Dr. Jade Irene Linardi, \\ E-mail: jade.irene@yahoo.com \\ Copyright: (C) the author(s), publisher and licensee Medip Academy. This is an open-access article distributed under \\ the terms of the Creative Commons Attribution Non-Commercial License, which permits unrestricted non-commercial \\ use, distribution, and reproduction in any medium, provided the original work is properly cited.
}

\begin{abstract}
Coronavirus disease 2019 (COVID-19) as a global pandemic has become a major burden especially in the health care system and economy. COVID-19 has clinical presentations ranging from remain asymptomatic to severe acute respiratory distress syndrome (ARDS) and death. All age groups are susceptible to this virus, but it seems that children with COVID-19 have milder symptoms than adults. Neonates, however, have been reported to have more severe cases compared to older children. There is also a possibility of vertical transmission from mothers to their neonates which could not be ignored. This review provides current knowledge of COVID-19 in neonates.
\end{abstract}

Keywords: Neonates, COVID-19, SARS-CoV-2

\section{INTRODUCTION}

The world has been encountered against coronavirus disease 2019 (COVID-19) pandemic caused by newly discovered severe acute respiratory syndrome coronavirus 2 (SARS-CoV-2) since its first case in December 2019 in China. ${ }^{1}$ To date, there were more than 116 million cumulative cases with around 2,5 million cumulative deaths of COVID-19 globally, thus had become a major burden whether in the health care system and economy. ${ }^{2}$ Children with COVID-19 had clinical manifestations that were less severe than adult patients, although they were still susceptible to infection, particularly infants. . $^{3,4}$

Neonates however are different from the older groups in terms of exposure to the virus. They could contract the virus through person-to-person transmission same as the older groups, but they possibly also contract the virus through vertical transmission before or at birth. ${ }^{4}$ There were limited data regarding neonates with COVID-19. However, several important aspects should be highlighted from these neonatal cases.

\section{SARS-CoV-2 PATHOGENESIS}

These positive sensed, enveloped, single-stranded coronaviruses belong to a family called Coronaviridae. They are divided into four genera based on their structure (alpha, beta, gamma, and delta). The coronaviruses that caused mild respiratory tract infections in humans such as common cold and croup are classified as alpha coronaviruses, while severe acute respiratory syndrome coronavirus 1 (SARS-CoV-1), middle east respiratory syndrome coronavirus (MERS-CoV), and SARS-CoV-2 are classified as beta coronaviruses. ${ }^{5,6}$ The SARS-CoV-2 has a genetic sequence similar to SARS-CoV-1 with $80 \%$ similarity, but even more alike to bat-derived coronaviruses with $88-89 \%$ similarity. ${ }^{7}$

Its envelope has several layers: spike glycoprotein (S), envelope (E), and membrane proteins $(\mathrm{M})$. The $\mathrm{S}$ protein acts as a media for the virus to enter and bind in the host cell. There is an S protein sub-unit called S1 that binds to angiotensin-converting enzyme 2 (ACE 2) receptor which is greatly expressed on type 2 alveolar cells in the lung and other places such as on esophageal epithelial cells, ileal, and colonic enterocytes. ${ }^{6,8}$ 


\section{MODE OF TRANSMISSION}

The predominant mechanism of transmission of SARSCoV-2 is via infected droplets from the respiratory tract. These droplets made direct or indirect contact with the nasal, conjunctival, or oral mucosa, and cause infection. This SARS-CoV-2 is highly contagious; it has a higher replicative number than SARS-CoV-1, making it spread much more efficient, and it also has a greater affinity for the respiratory tract and conjunctiva. ${ }^{6-8}$

In neonates, however, there is a possibility of vertical transmission, which is different from the adult and pediatric populations. Previous studies stated that neonates whose mother presented with COVID-19 at the third trimester of pregnancy had immunoglobulin $\mathrm{M}$ and $\mathrm{G}$ against SARS-CoV-2 at birth, thus, raising the concern of vertical transmission (intrauterine)..$^{9,10}$ The IgM antibody was produced during the late stage of fetus development, and it is too large to be passed through the placenta into the fetus; a positive $\operatorname{IgM}$ test at birth indicating an intrauterine of perinatal infection, while IgG could be passively passed from the mother to the fetus via the placenta. ${ }^{11}$

However, several reports found no convincing evidence of vertical transmission as the tests from vaginal mucus, amniotic fluid, placenta, cord blood, umbilical cord, and newborn stool specimens were negative for the SARSCoV-2. ${ }^{6,12,13}$ Moreover, as a comparison, a vertical transmission has been observed neither in SARS-CoV-1 nor MERS-CoV. ${ }^{14}$

\section{CLINICAL FEATURES}

Recent studies noted few neonates with confirmed COVID-19, with nonspecific, mild to moderate clinical presentation compared to adults or pediatric population. Predominant observed symptoms were fever or temperature instability, followed by gastrointestinal symptoms such as diarrhea and vomiting, abdominal distention, and poor feeding. ${ }^{15,16}$ The majority of neonates that were experiencing respiratory symptoms did not require intubation and mechanical ventilation. ${ }^{16} \mathrm{~A}$ study from Italy stated that only 1 out of 10 neonates with respiratory symptoms needed mechanical ventilation, but concomitant condition (prematurity) may have contributed to the clinical status, thus, cannot be excluded. ${ }^{15}$ Other symptoms are lethargy, poor feeding, and also rash with varied distributions. ${ }^{17}$ Neonates have been reported to have more severe cases $(10 \%-12 \%)$ compared to older children (3-4.8\%). ${ }^{17,18}$

\section{DIAGNOSIS}

Leukopenia and lymphopenia could be found in neonates with COVID-19, although leukocytosis and lymphocytosis were also found in several cases. Other findings may include mild thrombocytopenia, normal or mildly raised inflammatory markers (C-reactive proteins, procalcitonin), as well as elevated liver enzymes, creatine kinase, alkaline phosphatase, and lactate dehydrogenase. ${ }^{9,13,15,16}$ There were no specific radiologic features although it appeared milder compared to adults, with unilateral or bilateral infiltrates. The ground-glass opacities, multiple bilateral lobular and segmental consolidations in the peripheral lung particularly are shown more clearly by chest computer tomography than the chest $\mathrm{x}$-ray. ${ }^{13,16}$

The detection of the viral nucleic acid by reverse transcriptase-polymerase chain reaction (RT-PCR) in upper respiratory tract (URT; nasopharyngeal and oropharyngeal) samples are the gold standard for diagnosing COVID-19. Samples from the lower respiratory tract (LRT) have higher viral loads than samples from the URT, but those are more difficult to obtain. ${ }^{6,16}$ Some suggest that if the result from URT samples is negative, the test should be repeated using LRT samples whenever possible. ${ }^{17}$ The American Academy of Pediatrics (AAP) currently recommends the RT-PCR test should be performed at 24 hours and repeat at 48 hours (or a single test at 24-48 hours) in neonates who are born to mothers with suspected or confirmed COVID-19. ${ }^{19}$

\section{DELIVERY MANAGEMENT AND NEONATAL RESUSCITATION}

Ideally, pregnant women with suspected COVID-19 must be tested for SARS-CoV-2, while universal screening may be used in high prevalence areas. They should be designated to negative pressure delivery rooms, in which the mode of delivery is determined by obstetric indications. ${ }^{18,19}$ In a previous study of confirmed COVID19 mothers, there were $44 \%$ of neonates were born via caesarian sections, while another study noted that 18 of 19 neonates were also born via caesarian sections. Choice of delivery mode was not affected by SARS-CoV-2 test results. The most frequent indications for caesarian sections were the arrest of labor and non-reassuring fetal tracing. ${ }^{20,21}$ All health care workers have to use personal protective equipment (PPE) including a gown, gloves, an N95 respirator mask, and face shield or goggles. The least number of personnel should enter the delivery room while others standby outside the room, to minimize the exposure. Neonatal resuscitation should be performed as usual. Some studies advised to do immediate cord clamping due to possible vertical transmission, and also to take the infant as quickly as possible from his suspected/confirmed COVID-19 mother. However, the World Health Organization (WHO) endorses delayed cord clamping and early skin-to-skin contact. This decision-making should be discussed with parents after explaining the potential benefits and harms..$^{19,22}$

There are certain modifications in neonatal resuscitation particularly for some respiratory care practices due to a major concern regarding the aerosol-generating procedures, although the transmission risk has only been 
evaluated in adult cases, which includes T-piece and mask ventilation, bag and mask ventilation, nasal intermittent positive pressure ventilation (NIPPV), continuous positive airway pressure (CPAP), and mechanical ventilation. A viral/bacterial filter should be placed in those procedures, although there are risks of creating a greater dead space, especially in a small preterm infant (birth weight $1000 \mathrm{~g}$ ). For suctioning procedure, continuous suctioning is better than several episodes of intermittent suction in terms of reducing aerosol spread. During mask ventilation, it has been advised to use the 2-person technique with 1 person holding the mask with both hands to ensure a proper seal and reduce air leak, while the other person performing ventilation. The video laryngoscopy should be used whenever available to maintain some distance from the patient airway..$^{19,23}$

\section{BREASTFEEDING PRACTICE}

To date, there is no convincing evidence suggesting the virus can be transmitted via breast milk. ${ }^{14,19}$ Furthermore, breast milk has certain benefits that outweigh the potential transmission risk, in consideration that neonates typically have mild illness. Whenever possible, a mother should not be separated from her infant and direct breastfeeding is preferred (in case of the good condition of both the mother and her neonate). If the mother experiences a severe respiratory infection, they should be temporarily separated and expressed breast milk can be used (without pasteurization). The mother should be educated to always perform hand hygiene, breast hygiene, and wear a surgical face mask during breastfeeds or during expressing and storing the breast milk. ${ }^{19,24}$

\section{CONCLUSION}

In this brief review, recent data suggest that neonatal are also at risk of COVID-19, although vertical transmission is not convincing. There are challenges in recognizing neonates with COVID-19 because of unspecific clinical presentations, different from adult and pediatric cases. A SARS-CoV-2 test using RT-PCR must be performed in neonates born to suspected/confirmed COVID-19 mothers at recommended duration. Delivery management and resuscitation are performed with certain modifications. Breastfeeding is still a preferable choice but it depends on both the mother and her neonate's condition.

Funding: No funding sources Conflict of interest: None declared Ethical approval: Not required

\section{REFERENCES}

1. Zhu N, Zhang D, Wang W, Li X, Yang B, Song J, et al. A novel coronavirus from patients with pneumonia in China, 2019. New Engl J Med. 2020.
2. World Health Organization. COVID-19 weekly epidemiological update, 7 March 2021. Available at https://www.who.int/docs/default-

source/coronaviruse/situation-

reports/20210309_weekly_epi_update_30.pdf?sfvrs $\mathrm{n}=4 \mathrm{e} 7 \mathrm{da} 248 \_8 \&$ download=true. Accessed on 12 March 2021.

3. Dong Y, Mo X, Hu Y, Qi X, Jiang F, Jiang Z, et al. Epidemiology of covid-19 among children in China. Pediatrics 2020;145(6):e20200702.

4. Gale C, Quigley MA, Placzek A, Knight M, Ladhani S, Draper ES, et al. Characteristics and outcomes of neonatal SARS-CoV-2 infection in the UK: a prospective national cohort study using active surveillance. Lancet Child Adolesc Heal. 2021;5(2):113-21.

5. Yuki K, Fujiogi M, Koutsogiannaki S. Covid-19 pathophysiology: a review. Clinical Immunol. 2020;215:108427.

6. Kallem VR, Sharma D. COVID 19 in neonates. J Matern Fetal Neonatal Med 2020.

7. Ouassou H, Kharchoufa L, Bouhrim M, Daoudi NE, Imtara $\mathrm{H}$, Bencheikh $\mathrm{N}$, et al. The pathogenesis of coronavirus disease 2019 (covid-19): evaluation and prevention. J Immunol Res. 2020;1357983.

8. Cevik M, Kuppalli K, Kindrachuk J, Peiris M. Virology, transmission, and pathogenesis of SARSCoV-2. Bio Med J. 2020;371:m3862.

9. Dong L, Tian J, He S, Zhu C, Wang J, Liu C, et al. Possible vertical transmission of SARS-CoV-2 from an infected mother to her newborn. J Am Med Assoc 2020;323(18):1846-8.

10. Zeng H, Xu C, Fan J, Tang Y, Deng Q, Zhang W, et al. Antibodies in infants born to mothers with COVID-19 pneumonia. J Am Med Assoc. 2020;323(18):1848-9.

11. Wu YT, Liu J, Xu JJ, Chen YF, Yang W, Chen Y, et al. Neonatal outcome in 29 pregnant women with covid-19: a retrospective study in Wuhan, China. PLoS Med 2020;17(7):e1003195.

12. Kalyanasundaram S, Krishnamurthy K, Sridhar A, Narayanan VK, Santosh ABR,Rahman S. Novel corona virus pandemic and neonatal care: it's to early to speculate on impact. SN Compr Clin Med 2020;2:1412-8.

13. Zimmermann P, Curtis N. Covid-19 in children, pregnancy and neonates: a review of epidemiologic and clinical features. Pediatr Infect Dis J 2020;39:469-77.

14. Mimouni F, Lakshminrusimha S, Pearlman SA, Raju T, Gallagher PG, Mendlovic J. Perinatal aspects on the covid-19 pandemic: a practical resource for perinatal-neonatal specialists. J Perinatol 2020;40:820-6.

15. Trevisanuto D, Cavallin F, Cavicchiolo ME, Borellini M, Calgaro S, Baraldi E. Coronavirus infection in neonates: a systematic review. Arch Dis Child Fetal Neonatal Ed 2020;0:F1-6.

16. De Rose DU, Piersigilli F, Ronchetti MP, Santisi A, Bersani I, Dotta A, et al. Novel coronavirus disease 
(COVID-19) in newborns and infants: what we know so far. Ital J Pediatr 2020;46:56.

17. Nayak M, Panda S, Pradhan JB, Mohakud NK. Coronavirus disease 2019 in neonates - what is known and what needs to be known. Cureus 2020;12(8):e10171.

18. Amatya S, Corr TE, Gandhi CK, Glass KM, Kresch MJ, Mujsce DJ, et al. Management of newborns exposed to mothers with confirmed of suspected covid-19. J Perinatol 2020;40:987-96.

19. Sankaran D, Nakra N, Cheema R, Blumberg D, Lakshminrusimha S. Perinatal SARS-CoV-2 infection and neonatal covid-19: a 2021 update. Neo Reviews 2021;22(5)10.

20. Liu W, Wang J, Li W, Zhou Z, Liu S, Rong Z. Clinical characteristics of 19 neonates born to mothers with COVID-19. Front Med 2020;14:1938 .

21. Salvatore CM, Han JY, Acker KP, Tiwari P, Jin J, Brandler, et al. Neonatal management and outcomes during the COVID-19 pandemic: an observation cohort study. Lancet Child Adolesc Health 2020;4:721-7.

22. Stanojevic M. Are covid-19-positive mothers dangerous for their term and well newborn babies? Is there an answer? J Perinat Med 2020;48(5):441-5.

23. Shalish W, Lakshminrusimha S, Manzoni P, Keszler M, Sant'Anna GM. COVID-19 and neonatal respiratory care: current evidence and practical approach. Am J Perinatol 2020;37(8):780-91.

24. Davanzo R, Moro G, Sandri F, Agosti M, Moretti C, Mosca F. Breastfeeding and coronavirus disease2019: Ad interim indications of the Italian society of neonatology endorsed by the Union of European Neonatal \& Perinatal Societies. Matern Child Nutr 2020;16:e13010.

Cite this article as: Linardi JI. Coronavirus disease 2019 in neonates. Int J Contemp Pediatr 2021;8:7736. 